\title{
Recurrent Stroke in the Warfarin versus Aspirin in Reduced Cardiac Ejection Fraction (WARCEF) Trial
}

\author{
Patrick M. Pullicino ${ }^{a}$ Min Qian ${ }^{b}$ Ralph L. Sacco ${ }^{c}$ Ron Freudenberger ${ }^{d}$ \\ Susan Graham ${ }^{\mathrm{e}}$ John R. Teerlink ${ }^{\mathrm{f}}$ Douglas Mann ${ }^{g}$ Marco R. Di Tullio ${ }^{b}$ \\ Piotr Ponikowski ${ }^{\text {h }}$ Dirk J. Lok ${ }^{i}$ Stefan D. Ankerj Gregory Y.H. Lip ${ }^{k}$ \\ Conrado J. Estol' Bruce Levin ${ }^{\mathrm{b}}$ Jay P. Mohr ${ }^{\mathrm{b}}$ John L.P. Thompson ${ }^{\mathrm{b}}$ \\ Shunichi Hommab for the WARCEF Investigators \\ a University of Kent, Canterbury, UK; ${ }^{b}$ Columbia University, New York, N.Y., ' University of Miami, Miami, Fla.,

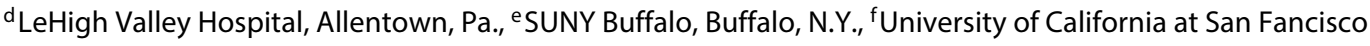

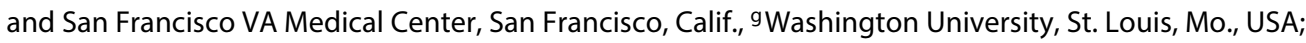 \\ ${ }^{h}$ Medical University, Wroclaw, Poland; 'Hospital Deventer, Deventer, The Netherlands; ${ }^{j}$ Charité Universitätsmedizin, \\ Campus-Virchow-Klinikum, Berlin, Germany; ${ }^{\mathrm{k}}$ The University of Birmingham Centre for Cardiovascular Sciences, \\ Birmingham, UK; 'Centro Neurológico de Tratamiento y Rehabilitación, Buenos Aires, Argentina
}

\section{Key Words}

Heart failure $\cdot$ Stroke $\cdot$ Ejection fraction

\begin{abstract}
Background and Purpose: WARCEF randomized 2,305 patients in sinus rhythm with ejection fraction (EF) $\leq 35 \%$ to warfarin (INR 2.0-3.5) or aspirin $325 \mathrm{mg}$. Warfarin reduced the incident ischemic stroke (IIS) hazard rate by $48 \%$ over aspirin in a secondary analysis. The IIS rate in heart failure $(\mathrm{HF})$ is too low to warrant routine anticoagulation but epidemiologic studies show that prior stroke increases the stroke risk in HF. In this study, we explore IIS rates in WARCEF patients with and without baseline stroke to look for risk factors for IIS and determine if a subgroup with an IIS rate high enough to give a clinically relevant stroke risk reduction can be identified. Methods: We compared potential stroke risk
\end{abstract}

factors between patients with baseline stroke and those without using the exact conditional score test for Poisson variables. We looked for risk factors for IIS, by comparing IIS rates between different risk factors. For EF we tried cut-off points of 10,15 and $20 \%$. The cut-off point $15 \%$ was used as it was the highest EF that was associated with a significant increase in IIS rate. IIS and EF strata were balanced as to warfarin/aspirin assignment by the stratified randomized design. A multiple Poisson regression examined the simultaneous effects of all risk factors on IIS rate. IIS rates per hundred patient years (/100PY) were calculated in patient groups with significant risk factors. Missing values were assigned the modal value. Results: Twenty of 248 (8.1\%) patients with baseline stroke and 64 of 2,048 (3.1\%) without had IIS. IIS rate in patients with baseline stroke (2.37/100PY) was greater than patients without $(0.89 / 100 \mathrm{PY})$ (rate ratio $2.68, \mathrm{p}<$ $0.001)$. Fourteen of $219(6.4 \%)$ patients with ejection fraction

\section{KARGER}

E-Mail karger@karger.com www.karger.com/ced (c) 2014 S. Karger AG, Basel

1015-9770/14/0383-0176\$39.50/0
Patrick Pullicino

KentHealth, Rutherford Building

University of Kent

Canterbury, CT2 7PD (UK)

E-Mail P.Pullicino@kent.ac.uk 
(EF) $<15 \%$ and 70 of 2,079 (3.4\%) with $E F \geq 15 \%$ had IIS. In the multiple regression analysis stroke at baseline $(p<0.001)$ and $\mathrm{EF}<15 \%$ vs. $\geq 15 \%$ ( $p=0.005)$ remained significant predictors of IIS. IIS rate was 2.04/100PY in patients with EF $<15 \%$ and $0.95 / 100 \mathrm{PY}$ in patients with $\mathrm{EF} \geq 15 \%(\mathrm{p}=0.009)$. IIS rate in patients with baseline stroke and reduced EF was 5.88/100PY with $\mathrm{EF}<15 \%$ decreasing to $2.62 / 100 \mathrm{PY}$ with $\mathrm{EF}$ $<30 \%$. Conclusions: In a WARCEF exploratory analysis, prior stroke and $\mathrm{EF}<15 \%$ were risk factors for IIS. Further research is needed to determine if a clinically relevant stroke risk reduction is obtainable with warfarin in $\mathrm{HF}$ patients with prior stroke and reduced $\mathrm{EF}$.

(c) 2014 S. Karger AG, Basel

\section{Introduction}

The warfarin versus aspirin in reduced cardiac ejection fraction (WARCEF) randomized 2,305 patients in sinus rhythm with ejection fraction $(\mathrm{EF}) \leq 35 \%$ to warfarin (INR 2.0-3.5) or aspirin $325 \mathrm{mg}$. Warfarin reduced the incident ischemic stroke (IIS) hazard rate by $48 \%$ over aspirin in a secondary analysis in terms of time to IIS (HR 0.52 ; $95 \%$ CI 0.33 to $0.82 ; \mathrm{p}=0.005$ in a stratified causespecific Cox model) [1]. Although this important finding is supported by a recent study [2], its clinical significance is difficult to assess due to several reasons: First, it is the result of a subgroup analysis, the primary combined endpoint (death, stroke and intracerebral hemorrhage) of WARCEF having been negative. Second, the reduction in IIS rate with warfarin over aspirin in WARCEF has been said to be offset by an increase in major systemic hemorrhages [3]. Third, we have found that the effect of warfarin on stroke in WARCEF is not homogenous and warfarin has a greater risk reduction effect in the cardio-embolic stroke subgroup [4].

The situation in atrial fibrillation (AF) bears similarities to that in HF in sinus rhythm [5]. The stroke risk reduction effect of warfarin is similar [6], but subgroups with a high risk for stroke have to be identified in whom the benefits of warfarin give a net clinical advantage. In AF, these subgroups have been defined by the use of scores, such as CHADS2 [7], for which there is no counterpart in HF. A recent study [8] using the decision analysis methodology showed that patients require at least a $0.8 \%$ absolute risk reduction (number needed to treat 125 ) in order to agree to initiate anticoagulation treatment. A 0.52 hazard rate with warfarin would not achieve this absolute risk reduction in patients with heart failure (HF) in sinus rhythm, who have stroke rates of $0.8-1.5 \%$ per year $[2,9]$. Although a previous incident of stroke also appears to increase the stroke rate in HF [10], it is unclear whether patients with recurrent stroke or some subgroup of them, would have a rate high enough to warrant routine anticoagulation. This study was initiated to look for risk factors for IIS and at the rate of IIS in patients with prior stroke in WARCEF to determine if a subgroup with a higher stroke rate can be identified.

\section{Methods}

The primary outcome of this post-hoc analysis was the onset of IIS, previously defined [1]. We investigated the risk factors for IIS, comparing the IIS rates between patients with and without different potential stroke risk factors in the WARCEF baseline data (see table 1) using Poisson regression. For EF, we assessed cut-off points of 10,15 and $20 \%$. The cut-off point $15 \%$ was used as it was the highest EF showing a significant increase in the IIS rate. IIS and EF strata were balanced as to warfarin/aspirin assignment by the stratified randomized design. A multiple Poisson regression examined the simultaneous effects of all risk factors on the IIS rate. We also compared the IIS rate per hundred patient years (/100PY) between the group with $\mathrm{EF}<15 \%$ versus the group with $\mathrm{EF} \geq 15 \%$ in patients with and without baseline stroke. p values and 95\% CIs were calculated based on the Wald test. The missing values were assigned the modal value. IIS rates were calculated for different EF levels in patients with baseline stroke.

\section{Results}

Twenty of $248(8.1 \%)$ patients with baseline stroke and 64 of 2,048 (3.1\%) without had IIS. Descriptive statistics (according to onset of IIS) for the demographic and clinical covariates are shown in table 1. Results from univariable and multivariable Poisson regression are presented in table 2 . For EF, $15 \%$ was the highest $\mathrm{EF}$ that was associated with a significant increase in the IIS rate $(p=0.064$ at cutoff point $10 \%, \mathrm{p}=0.009$ at $15 \%$, and $\mathrm{p}=0.261$ at $20 \%)$. Only baseline stroke and $\mathrm{EF}<15 \%$ were significant risk factors for IIS in the univariable and multivariable models. IIS rates in patients with baseline stroke $(2.37 / 100 \mathrm{PY})$ were greater compared to the IIS rates in patients without baseline stroke $(0.89 / 100 \mathrm{PY})$ : unadjusted $\mathrm{RR}=2.68, \mathrm{p}<0.001$; adjusted $\mathrm{RR}=2.66, \mathrm{p}<0.001$. Fourteen of $219(6.4 \%)$ patients with $\mathrm{EF}<15 \%$ and 70 of 2,079 (3.4\%) with $\mathrm{EF} \geq 15 \%$ had IIS. IIS rates were $2.04 / 100 \mathrm{PY}$ in patients with $\mathrm{EF}<15 \%$ and $0.95 / 100 \mathrm{PY}$ in patients with $\mathrm{EF} \geq 15 \%$ (unadjusted $\mathrm{RR}=2.15, \mathrm{p}=0.009$; adjusted $\mathrm{RR}=2.33, \mathrm{p}=0.005)$. Comparison of IIS rates between groups with $\mathrm{EF}<15 \%$ versus $\mathrm{EF} \geq 15 \%$ in patients 
Table 1. Baseline characteristics of the study participants, according to the onset of IIS

\begin{tabular}{|c|c|c|c|}
\hline Covariates & IIS $(n=84)$ & No IIS $(n=2,221)$ & $\mathrm{p}$ value* \\
\hline Older patients (age $\geq 60$ ) & $46 / 84(54.8)$ & $1,229 / 2,221(55.3)$ & 0.917 \\
\hline Male & $66 / 84(78.6)$ & $1,774 / 2,216(80.1)$ & 0.739 \\
\hline White non-Hispanic & $64 / 84(76.2)$ & $1,669 / 2,215(75.3)$ & 0.861 \\
\hline Continent & & & 0.508 \\
\hline EU & $36 / 84(42.9)$ & $1,058 / 2,221(47.6)$ & \\
\hline NA & $43 / 84(51.2)$ & $1,076 / 2,221(48.4)$ & \\
\hline Systolic BP $\geq 119.5$ & $51 / 84(60.7)$ & $1,374 / 2,215(62.0)$ & 0.807 \\
\hline Ejection fraction $<15 \%$ & $14 / 84(16.7)$ & $205 / 2,214(9.3)$ & 0.023 \\
\hline NYHA class III or IV & $27 / 84(32.1)$ & $681 / 2,206(30.9)$ & 0.804 \\
\hline Alcohol consumption & & & 0.755 \\
\hline Current consumption, $>2 \mathrm{oz} /$ day & $18 / 83(21.7)$ & $554 / 2,215(25.0)$ & \\
\hline Previous consumption, $>2 \mathrm{oz} /$ day & $18 / 83(21.7)$ & $488 / 2,215(22.0)$ & \\
\hline Smoking status & & & 0.989 \\
\hline Current smoker & $15 / 83(18.1)$ & $393 / 2,213(17.8)$ & \\
\hline Former smoker & $42 / 83(50.6)$ & $1,138 / 2,213(51.4)$ & \\
\hline Already on warfarin & $8 / 84(9.5)$ & $171 / 2,221(7.7)$ & 0.540 \\
\hline Atrial fibrillation & $3 / 84(3.6)$ & $83 / 2,211(3.8)$ & 0.931 \\
\hline Diabetes mellitus & $31 / 84(36.9)$ & $691 / 2,210(31.3)$ & 0.275 \\
\hline Hypertension & $49 / 81(60.5)$ & $1,318 / 2,151(61.3)$ & 0.888 \\
\hline Ischemic cardiomyopathy & $37 / 84(44.0)$ & $954 / 2,209(43.2)$ & 0.876 \\
\hline Baseline stroke & $20 / 84(23.8)$ & $228 / 2,212(10.3)$ & $<0.001$ \\
\hline Myocardial infarction & $47 / 84(56.0)$ & $1,065 / 2,210(48.2)$ & 0.162 \\
\hline Peripheral vascular disease & $14 / 84(16.7)$ & $247 / 2,221(11.1)$ & 0.115 \\
\hline
\end{tabular}

Table 2. Predictors of IIS rate in univariable and multivariable Poisson regression models

\begin{tabular}{|c|c|c|c|c|}
\hline Covariates & rate ratio $(95 \% \mathrm{CI})$ & p value* & rate ratio $(95 \% \mathrm{CI})$ & p value* \\
\hline Male & $0.96(0.57,1.61)$ & 0.869 & $0.96(0.55,1.66)$ & 0.875 \\
\hline White, non-Hispanic & $1.03(0.63,1.71)$ & 0.893 & $0.99(0.58,1.69)$ & 0.981 \\
\hline Systolic BP $\geq 119.5$ & $0.95(0.61,1.48)$ & 0.827 & $0.96(0.61,1.52)$ & 0.874 \\
\hline Alcohol consumption & & 0.637 & & 0.740 \\
\hline Current consumption, $>2 \mathrm{oz} /$ day & $0.79(0.46,1.35)$ & & $0.86(0.49,1.51)$ & \\
\hline Previous consumption, $>2 \mathrm{oz} /$ day & $0.85(0.49,1.45)$ & & $0.81(0.45,1.45)$ & \\
\hline Smoking status & & 0.992 & & 0.977 \\
\hline Current smoker & $0.98(0.52,1.84)$ & & $0.93(0.47,1.84)$ & \\
\hline Former smoker & $0.97(0.60,1.58)$ & & $0.95(0.57,1.60)$ & \\
\hline Ischemic cardiomyopathy & $1.20(0.78,1.84)$ & 0.415 & $0.96(0.58,1.60)$ & 0.887 \\
\hline Myocardial infarction & $1.42(0.92,2.18)$ & 0.111 & $1.36(0.81,2.28)$ & 0.249 \\
\hline Peripheral vascular disease & $1.74(0.98,3.09)$ & 0.058 & $1.59(0.87,2.89)$ & 0.132 \\
\hline Baseline stroke & $2.68(1.62,4.42)$ & $<0.001$ & $2.66(1.59,4.45)$ & $<0.001$ \\
\hline
\end{tabular}

* p values were calculated using the Wald test. Score tests for overdispersion were not significant. 
Table 3. IIS rate by baseline stroke and EF categories

\begin{tabular}{lcccc}
\hline & $\mathrm{EF}<15 \%$ & $\mathrm{EF} \geq 15 \%$ & Rate ratio & p value* \\
\hline With baseline stroke, PY & $51.0(\mathrm{n}=21)$ & $793.4(\mathrm{n}=227)$ & & \\
$\quad$ Events, $\mathrm{n}(\mathrm{n} / 100 \mathrm{PY})$ & $3(5.88)$ & $17(2.14)$ & 2.75 & 0.107 \\
Without baseline stroke, PY & $635.7(\mathrm{n}=198)$ & $6,597.4(\mathrm{n}=1,859)$ & & 0.021 \\
Events, $\mathrm{n}(\mathrm{n} / 100 \mathrm{PY})$ & $11(1.73)$ & $53(0.80)$ & 2.15 & 0.15 \\
\hline
\end{tabular}

* p values were calculated using the Wald test.

Table 4. Warfarin/aspirin effect by the presence of prior ischemic stroke

\begin{tabular}{lcccc}
\hline & Warfarin & Aspirin & Rate ratio & p value* \\
\hline With baseline stroke, PY & $444.7(\mathrm{n}=128)$ & $399.7(\mathrm{n}=120)$ & & 0.262 \\
$\quad$ Events, $\mathrm{n}(\mathrm{n} / 100 \mathrm{PY})$ & $8(1.80)$ & $12(3.00)$ & 0.60 & 0.008 \\
Without baseline stroke, PY & $3,600(\mathrm{n}=1,014)$ & $3,633.1(\mathrm{n}=1,043)$ & & 0.49 \\
$\quad$ Events, $\mathrm{n}(\mathrm{n} / 100 \mathrm{PY})$ & $21(0.58)$ & $43(1.18)$ & & \\
\hline * p values were calculated using the Wald test. & & & \\
\hline
\end{tabular}

Table 5. Warfarin/aspirin effect by EF categories

\begin{tabular}{lcccc}
\hline & Warfarin & Aspirin & Rate ratio & p value* \\
\hline EF $<15 \%$, PY & $341.5(\mathrm{n}=110)$ & $345.2(\mathrm{n}=109)$ & & 0.580 \\
Events, $\mathrm{n}(\mathrm{n} / 100 \mathrm{PY})$ & $8(2.34)$ & $6(1.74)$ & 1.35 & 0.001 \\
$\mathrm{EF} \geq 15 \%, \mathrm{PY}$ & $3,703.2(\mathrm{n}=1,032)$ & $3,687.6(\mathrm{n}=1,054)$ & & 0.43 \\
Events, $\mathrm{n}(\mathrm{n} / 100 \mathrm{PY})$ & $21(0.57)$ & $49(1.33)$ & & \\
\hline$*$ p values were calculated using the Wald test. & & & \\
\hline
\end{tabular}

with and without baseline stroke are presented in table 3 . The IIS rate among the 21 patients with baseline stroke and $\mathrm{EF}<15 \%$ was $5.88 / 100 \mathrm{PY}$ and in patients without baseline stroke and EF $<15 \%$ was $1.73 / 100 \mathrm{PY}$. Table 4 shows the warfarin/aspirin effect by the presence of prior ischemic stroke. Table 5 shows the warfarin/aspirin effect by EF categories.

\section{Discussion}

We found that $\mathrm{EF}<15 \%$ is a risk factor for IIS in HF in sinus rhythm. This is a new finding but previous studies have suggested that $\mathrm{EF}<20 \%$ is a risk factor for stroke
[11]. We have also confirmed previous studies $[9,10]$ showing prior stroke to be a risk factor for stroke in HF. Unlike previous studies, we did not find age [9], diabetes $[9,10]$ or hypertension [12], to be risk factors for IIS in HF. In addition to prior stroke (and HF), risk factors for stroke in HF in sinus rhythm are therefore different from those in $\mathrm{AF}$.

A warfarin stroke risk reduction effect was not apparent in the WARCEF primary endpoint because it included a large number of deaths not reduced by warfarin. However, stroke in HF can be fatal and is disabling [4] and should be assessed for treatment in its own right. Although there were more major hemorrhages in the warfarin than aspirin arms in WARCEF, it is only intracere- 
bral and not a major systemic hemorrhage that offsets a risk reduction effect of warfarin because nonfatal systemic hemorrhage is treatable [4]. A recent study has shown that patients are willing to sustain 4.4 major systemic hemorrhages to prevent one stroke [8]. The rate of major systemic hemorrhage in WARCEF was well below this rate.

In WARCEF, warfarin gave a hazard ratio of 0.52 for IIS versus aspirin and patients on warfarin had 0.07 intracerebral hemorrhage events/100PY more than aspirin. We found a rate of IIS of 5.88/100PY in patients with both prior stroke and $\mathrm{EF}<15 \%$, which is a rate similar to that of patients with AF with a moderate stroke risk [7] and who are routinely anticoagulated. This suggests that there are subgroups of patients with HF with a stroke rate high enough to have a clinically relevant benefit from anticoagulation. The rate of IIS in all patients with baseline stroke $(2.37 / 100 \mathrm{PY})$ is still however quite low, and we did not find a significant stroke risk reduction effect by warfarin over aspirin in this subgroup; so we cannot advise anticoagulation of all HF patients with prior stroke. Our findings are based on small numbers and hence do need confirmation in a separate population, preferably in patients who are not on antithrombotics. We are planning a similar analysis in the warfarin versus Antiplatelet Therapy in Chronic Heart Failure (WATCH) Study [2].

Since AF is a strong risk factor for stroke and paroxysmal AF gives a similar risk to overt AF, the question arises whether the increased stroke risk in HF in sinus rhythm could be totally or partly due to undiagnosed paroxysmal AF. Patients with a prior history of AF or AF on baseline electrocardiogram were excluded from WARCEF. None of the 84 patients with IIS in WARCEF had overt atrial fibrillation. Non-invasive cardiac monitoring in patients with acute stroke detects up to $7.7 \%$ of patients to have paroxysmal AF [13]. About 6 of the IIS in WARCEF could therefore have been due to paroxysmal AF on this basis. If paroxysmal AF accounted for more than a small proportion of patients with IIS we would have expected known risk factors for AF including hypertension, diabetes and particularly age, to become significant risk factors for IIS in HF too.

The major limitation of this study is that the number of patients with both prior stroke and $\mathrm{EF}<15 \%$ is very small and represents only $9 \%$ of patients with prior stroke. The group was too small to show a significant warfarin hazard ratio. We have recently reported that the warfarin effect is the greatest in the cardioembolic stroke subtype in WARCEF [4] and strokes with $\mathrm{EF}<15 \%$ are likely to be cardioembolic. Mortality and intracerebral hemorrhage rates could however be greater in this subgroup. Although the overall impact of treating this small subgroup with warfarin would be small, our findings do establish the presence of a high stroke risk subgroup in patients with HF. Thrombin inhibitors need to be studied in HF in sinus rhythm since the current guidelines [14] recommend their use in AF with a thromboembolic rate 2.5 [1.983.15]/100PY. This rate is similar to the rate of IIS in all HF patients with baseline stroke in WARCEF and potentially gives a larger subgroup in which anticoagulation with these agents might be clinically indicated.

\section{Acknowledgement}

See online supplementary investigator list (www.karger.com/ doi/10.1159/000365502).

\section{Sources of Funding}

NINDS U01-NS-043975 and U01-NS-039143.

\section{References}

$>1$ Homma S, Thompson JL, Pullicino PM, Levin B, Freudenberger RS, Teerlink JR, Ammon SE, Graham S, Sacco RL, Mann DL, Mohr JP, Massie BM, Labovitz AJ, Anker SD, Lok DJ, Ponikowski P, Estol CJ, Lip GY, Di Tullio MR, Sanford AR, Mejia V, Gabriel AP, del Valle ML, Buchsbaum R: Warfarin and aspirin in patients with heart failure and sinus rhythm. N Engl J Med 2012;366:18591869.

-2 Massie BM, Collins JF, Ammon SE, Armstrong PW, Cleland JG, Ezekowitz M, Jafri SM, Krol WF, O’Connor CM, Schulman KA,
Teo K, Warren SR: Randomized trial of warfarin, aspirin, and clopidogrel in patients with chronic heart failure: the Warfarin and Antiplatelet Therapy in Chronic Heart Failure (WATCH) trial. Circulation 2009;119:16161624.

3 Eikelboom JW, Connolly SJ: Warfarin in heart failure. N Engl J Med 2012;366:19361938.

-4 Pullicino PM, Thompson JLP, Sacco RL, Sanford AR, Qian K, Teerlink JR, Haddad H, Diek M, Freudenberger RS, Labovitz AJ, Di Tullio MR, Lok DJ, Ponikowski P, Anker SD,
Graham S, Mann DL, Mohr JP, Homma S: Stroke in heart failure in sinus rhythm: the Warfarin versus Aspirin in Reduced Ejection Fraction trial. Cerebrovasc Dis 2013;36:7478.

5 Pullicino P, Homma S: Stroke in heart failure: atrial fibrillation revisited? J Stroke Cerebrovasc Dis 2010;19:1-2.

6 Hart RG, Benavente O, McBride R, Pearce LA: Antithrombotic therapy to prevent stroke in patients with atrial fibrillation: a meta-analysis. Ann Intern Med 1999;131: 492-501. 
7 Singer DE, Chang Y, Fang MC, Borowsky LH, Pomernacki NK, Udaltsova N, Go AS: The net clinical benefit of warfarin anticoagulation in atrial fibrillation. Ann Intern Med 2009;151: 297-305.

8 Lahaye S, Regpala S, Lacombe S, Sharma M, Gibbens S, Ball D, Francis K: Evaluation of patients' attitudes towards stroke prevention and bleeding risk in atrial fibrillation. Thromb Haemost 2014;111:465-473.

-9 Witt BJ, Brown RD Jr, Jacobsen SJ, Weston SA, Ballman KV, Meverden RA, Roger VL: Ischemic stroke after heart failure: a communitybased study. Am Heart J 2006;152:102-109.
0 Pullicino PM, McClure LA, Howard VJ, Wadley VG, Safford MM, Meschia JF, Anderson A, Howard G, Soliman EZ: Identifying a high stroke risk subgroup in individuals with heart failure. J Stroke Cerebrovasc Dis 2013; 22:620-626.

11 Pullicino P, Raynor S: Is low cardiac ejection fraction a risk factor for stroke? Malta Medical Journal 2013;25:10-17.

12 Dries DL, Rosenberg YD, Waclawiw MA, Domanski MJ: Ejection fraction and risk of thromboembolic events in patients with systolic dysfunction and sinus rhythm: evidence for gender differences in the studies of left ventricular dysfunction trials. J Am Coll Cardiol 1997;29:1074-1080.
3 Liao J, Khalid Z, Scallan C, Morillo C, O’Donnell M: Noninvasive cardiac monitoring for detecting paroxysmal atrial fibrillation or flutter after acute ischemic stroke: a systematic review. Stroke 2007;38:29352940.

4 Furie KL, Goldstein LB, Albers GW, Khatri P, Neyens R, Turakhia MP, Turan TN, Wood KA: Oral antithrombotic agents for the prevention of stroke in nonvalvular atrial fibrillation: a science advisory for healthcare professionals from the American Heart Association/American Stroke Association. Stroke 2012;43:3442-3453. 